See Article page 274

\section{Commentary: Sarcomas and sarcomatoid tumors of the lung...not your average lung cancers}

\author{
Smita Sihag, MD, MPH
}

In their manuscript, Robinson and colleagues ${ }^{1}$ put forth a 20-year retrospective case series of 100 consecutive patients with primary pulmonary sarcomas $(\mathrm{N}=45)$ and carcinosarcomas $(\mathrm{N}=55)$, both of which represent rare tumors of the lung with an incidence less than $1 \%$. By reputation, these tumors are known to be locally aggressive, often requiring more extensive lung resections, with poor responses to systemic therapy. Given their rarity and the resultant paucity of data, the question remains whether these should be approached any differently from the average non-small cell lung cancer, ie, lung adenocarcinoma. The short answer, based on this study and others, is probably not, but the clinicopathologic behavior of these tumors is clearly different, with a worse prognosis stage-forstage, and thus a few important points deserve mention.

The first point is that this study affirms that surgery should likely remain the mainstay of treatment for these tumors if technically resectable. For pulmonary carcinosarcomas, surgery leads to a 5-year survival of approximately $30 \%$, which is supported by a larger Surveillance, Epidemiology, and End Results (SEER) database study. ${ }^{2}$ The SEER database study also suggests a far-worse prognosis in surgically unresectable disease, whereas Robinson and colleagues demonstrate a similar 5-year survival in nonsurgical patients treated with chemotherapy, radiotherapy, and/or immunotherapy. Surgical resection confers a comparable 5 -year survival of nearly $30 \%$ for primary pulmonary sarcomas as well in comparison with $8 \%$

\footnotetext{
From the Thoracic Service, Department of Surgery, Memorial Sloan Kettering Cancer Center, New York, NY.

Disclosures: The author reported no conflicts of interest.

The Journal policy requires editors and reviewers to disclose conflicts of interest and to decline handling or reviewing manuscripts for which they may have a conflict of interest. The editors and reviewers of this article have no conflicts of interest.

Received for publication April 20, 2020; accepted for publication April 21, 2020; available ahead of print May 1, 2020.

Address for reprints: Smita Sihag, MD, MPH, Memorial Sloan-Kettering Cancer Center, 1275 York Ave, C-881, New York, NY 10065 (E-mail: sihags@mskcc.org). J Thorac Cardiovasc Surg 2021;162:285-6 $0022-5223 / \$ 36.00$

Copyright (c) 2020 by The American Association for Thoracic Surgery https://doi.org/10.1016/j.jtcvs.2020.04.082
}
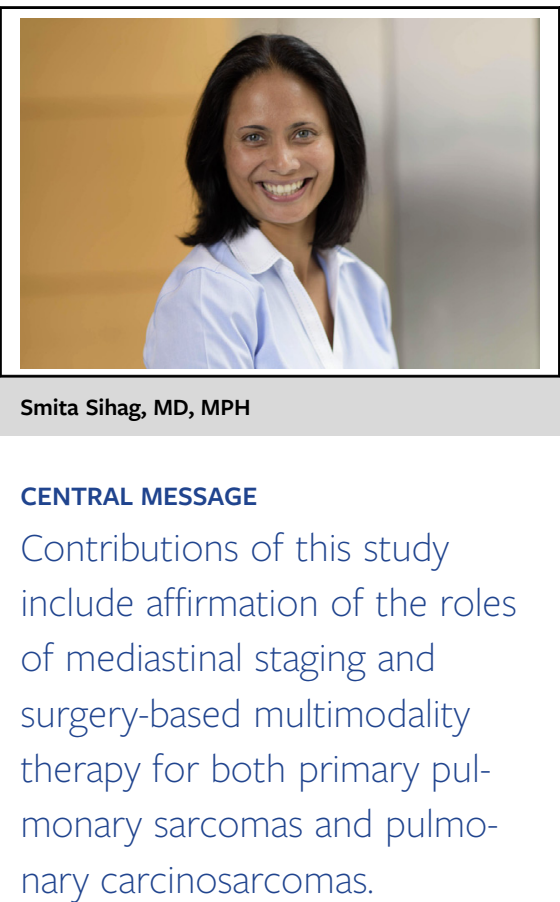

in unresectable disease, according to this study and another previous SEER database study. ${ }^{3}$ It is worth noting that most patients presented with tumors $>5 \mathrm{~cm}$ in size and almost one half of surgical patients required either a pneumonectomy or chest wall resection. Still yet, roughly $20 \%$ had an R1 resection and required adjuvant therapy. With respect to these characteristics, pulmonary carcinosarcomas may have more in common with primary pulmonary sarcomas rather than non-small cell lung cancers, although they are histopathologically classified as such. ${ }^{4}$

The second point is that invasive mediastinal staging should be carefully considered in all patients with pulmonary carcinosarcoma, regardless of stage potentially, whereas only in select patients with primary pulmonary sarcoma with suspicious findings on imaging. Although the sample size is limited, $44 \%$ of pulmonary carcinosarcomas had nodal involvement, including $36 \%$ with $\mathrm{N} 2$ disease. A clear relationship between tumor size and nodal involvement was not apparent here, thereby suggesting that perhaps all of these patients should undergo invasive mediastinal staging upfront. By contrast, only $18 \%$ of patients with primary pulmonary sarcoma had nodal involvement, and only 2 patients were found to have N2 disease. Despite a poorer prognosis, the incidence of nodal disease appears to be lower stagefor-stage than typical non-small cell lung cancers.

The last point is that multimodality therapy may play a more prominent role in treating these tumors than 
previously acknowledged. For primary pulmonary sarcoma, 7 of 8 patients who were treated with induction chemotherapy had at least a partial response to chemotherapy, including one complete response, surprisingly. Very few patients with pulmonary carcinosarcoma were treated with induction therapy in this cohort, but patients with more advanced disease were treated with chemotherapy, radiotherapy, and/or immunotherapy if positive for PDL-1 expression, with remarkably similar survival as surgical patients as noted previously. This finding does not undermine the role of surgery but rather enhances the argument for multimodality treatment in my view. Given these results and a high rate of R1 resection, induction therapy should be considered more often.

In conclusion, the 3 main take-home messages of this study are that (1) surgery is the mainstay of treatment, (2) invasive mediastinal staging should be strongly considered in pulmonary carcinosarcomas, and (3) multimodality therapy including possibly immunotherapy may have an enhanced role in both histologies. The level of evidence is low, but any prospective study examining these rare tumors will be challenging.

\section{References}

1. Robinson LA, Tanvetyanon T, Henderson-Jackson E, Bui MM, Druta M. Results of treating primary pulmonary sarcomas and pulmonary carcinosarcomas. J Thorac Cardiovasc Surg. 2021;162:274-84.

2. Ersek JL, Symanowski JT, Han Y, Howard A, Dumas K, Ahrens W, et al. Pulmonary carcinosarcoma: a surveillance, epidemiology, and end results (SEER) analysis. Clin Lung Cancer. 2020;21:160-70.

3. Spraker MB, Bair E, Bair R, Connell PP, Mahmood U, Koshy M. An analysis of patient characteristics and clinical outcomes in primary pulmonary sarcoma. J Thorac Oncol. 2013;8:147-51

4. Travis WD, Brambilla E, Nicholson AG, Yatabe Y, Austin JHM, Beasley MB, et al. The 2015 World Health Organization Classification of lung tumors: impact of genetic, clinical and radiologic advances since the 2004 classification. J Thorac Oncol. 2015;10:1243-60.
See Article page 274 .

\section{Commentary: Primary pulmonary sarcomas and pulmonary carcinosarcomas, challenging and enigmatic, but treatable!}

\author{
Lawek Berzenji, MD, and Paul E. Van Schil, MD, PhD
}

Primary pulmonary sarcomas (PPS) and pulmonary carcinosarcomas (PCS) are rare, sarcomatous subtypes of lung cancer. They display more aggressive features than the more common non-small cell lung cancers (NSCLC). According to the World Health Organization classification of tumors, sarcomatoid carcinomas account for $0.1 \%$ to $0.4 \%$ of all lung cancers. Furthermore, only $4 \%$ of this subgroup are PCS. ${ }^{1}$ Similarly, PPS accounts for $<0.5 \%$ of all

\footnotetext{
From the Department of Thoracic and Vascular Surgery, Antwerp University Hospital and Antwerp University, Antwerp, Belgium.

Disclosures: Authors have nothing to disclose with regard to commercial support.

Received for publication March 27, 2020; revisions received March 27, 2020; accepted for publication March 30, 2020; available ahead of print April 11, 2020. Address for reprints: Paul E. Van Schil, MD, PhD, Department of Thoracic and Vascular Surgery, Antwerp University Hospital, Wilrijkstraat 10, B-2650, Edegem (Antwerp), Belgium (E-mail: paul.van.schil@uza.be).

J Thorac Cardiovasc Surg 2021;162:286-7

$0022-5223 / \$ 36.00$

Copyright (c) 2020 by The American Association for Thoracic Surgery

https://doi.org/10.1016/j.jtcvs.2020.03.138
}

Check for updates

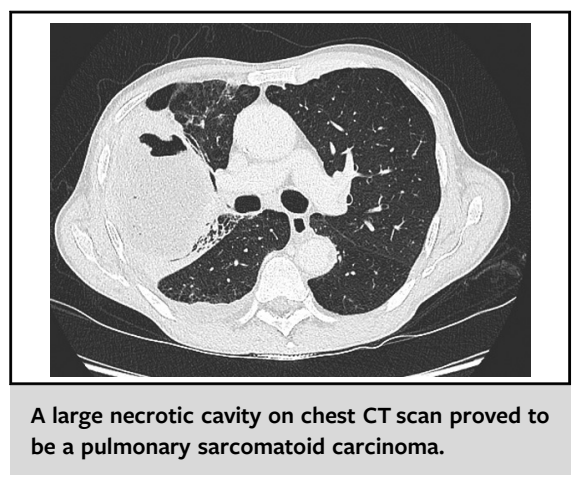

CENTRAL MESSAGE

Primary pulmonary sarcomas

and carcinosarcomas are rare

tumors with a poorer outcome

compared to more common

non-small cell lung cancers.

Multimodality treatment is indi-

cated to improve prognosis.

lung cancers. ${ }^{2}$ Clinical and imaging features of PPS and PCS are similar to other subtypes of NSCLC. However, they often present with locoregional invasion and distant metastases. Due to their more aggressive behavior, both PPS and PCS have a relatively poor prognosis compared 